\title{
Role of facilitative glucose uptake in the glucose-inorganic phosphate-mediated retardation and inhibition of development in different strains of mouse embryos
}

\author{
L. Scott ${ }^{*}$ and D. G. Whittingham ${ }^{2}$ \\ ${ }^{1}$ Division of Reproductive Endocrinology, Department of Obstetrics and Gynecology, \\ Sinai Hospital of Baltimore, Baltimore, Maryland 21215, USA; and ${ }^{2}$ Department of Anatomy \\ and Developmental Biology, St George's Hospital Medical School, London SW17 ORE, UK
}

Mouse embryos from different strains develop differently in vitro depending on the composition of the culture medium, and in particular on the presence or absence of glucose and inorganic phosphate. Glucose is both stimulatory and inhibitory in certain conditions. Glucose uptake by cells can be passive, down concentration gradients, or active, through sodium driven pumps, or can occur through facilitative transport. This study investigated the effects of inhibition of facilitative glucose transport on the glucose-inorganic phosphate-mediated blocks in development in three different strains of mouse embryo, CF-1, CD-1 and an $F_{2}$ hybrid. Development of CF-1 and CD-1 embryos is blocked in medium containing glucose and inorganic phosphate but not in medium containing glucose alone, and $F_{2}$ embryos are not affected.
Inhibition of facilitated glucose transport to the eightcell-morula stage in CF-1 and CD-1 embryos resulted in development in medium containing both glucose and inorganic phosphate, indicating that the prevention of facilitative glucose uptake can overcome the developmental block. Removal of inhibition before the eightcell-morula stage resulted in total arrest of CF-1 embryos and minimum development of CD-1 embryos. $F_{2}$ embryos are not affected by inorganic phosphate and glucose and showed no response to the transporter inhibitor at any stage. These data support the contention that facilitated glucose transport is active in embryos, is phosphatedependent and that its inhibition can overcome the glucose-inorganic phosphate-mediated developmental blocks in mouse embryos.

\section{Introduction}

Glucose and inorganic phosphate affect development of mouse embryos in vitro, acting in both an inhibitory and stimulatory manner. CF-1, CD-1 and $F_{2}$ mouse embryos react to these constituents in different ways. Embryos of CF1 and CD-1 mice, two random bred strains from different genetic backgrounds that show developmental blocks in traditional embryo culture media, are able to develop in vitro if inorganic phosphate is removed from the culture medium, regardless of the presence or absence of glucose (Scott and Whittingham, 1996). Glucose has a stimulatory effect on the later developmental stages of many mouse strains (Brown and Whittingham, 1992; Gardner and Sakkas, 1993; Chatot et al., 1994; Scott and Whittingham, 1996) and specifically in CF-1, CD-1 and $F_{2}$ strains (L. Scott and D. G. Whittingham, unpublished). However, if CF-1 or CD-1 embryos are grown initially without glucose and inorganic phosphate and these constituents are introduced into the culture system before the eight-cell stage, the

\footnotetext{
*Present address: The ART Institute of Washington, Inc., Walter Reed Army Medical Center, PO Box 59727, Washington, DC 20012, USA Email: lynette.scott@na.amedd.army.mil
}

embryos stop growing and become atretic. At later developmental stages the introduction of glucose is beneficial (Brown and Whittingham, 1992; Gardner and Sakkas, 1993; L. Scott and D. G. Whittingham, unpublished). It has also been shown that there is a concentration effect of both glucose and inorganic phosphate on mouse embryos, which is strain-dependent (L. Scott and D. G. Whittingham, unpublished).

The mechanisms responsible for the inhibition and retardation of development operate at the level of metabolism of the embryo. In early development, mouse embryos rely on the tricarboxylic acid cycle (TCA) for energy production, primarily using pyruvate as a metabolic substrate. The switch to glycolysis occurs after the embryonic genome has been activated, at or close to compaction (Brinster, 1965a,b; Biggers et al., 1967; Leese, 1991; Gardner and Sakkas, 1993). The inability of the embryo to use glucose is due to the low concentrations of phosphofructokinase that are present in early embryos. Embryos are able to take up glucose, which is then phosphorylated by hexokinase, using energy, but it cannot be metabolized further owing to the lack of phosphofructokinase (Houghton et al., 1996). This situation results in a depletion of ATP and a build up of glucose, which cannot be used. This activity is driven by the presence of inorganic 
phosphate, the absence of which allows the feedback regulation of hexokinase by its end product, glucose-6phosphate.

Glucose can enter an embryo through three mechanisms: (i) passive transport down a concentration gradient, primarily using water channels, (ii) facilitated entry using facilitated transport molecules; and (iii) active transport through specific glucose pumps. Embryos take up glucose in both a passive and facilitative manner from the one-cell stage (Gardner and Leese, 1988; Leppens-Luisier et al., 2001), but do not use active transport, which is sodiumdependent, until the morula-blastocyst stages (Chi et al., 1993; Pantaleon et al., 1997; Carayannopoulos et al., 2000). There are many isoforms of the glycoproteins that form the facilitative, non-active, sodium-independent glucose transport system; glucose transporter 1 (GLUT-1), GLUT-2, GLUT-3 and GLUT-8 have been described in mouse embryos. The exception is GLUT-4, which is sodiumdependent, but this isoform has not been found in preimplantation mammalian embryos (Hogan et al., 1991). Each transporter is active at different times. GLUT-1 is active throughout development (Carayannopoulos et al., 2000; Pantaleon et al., 2001). GLUT-1 is distributed uniformly throughout the embryo at precompaction stages, localizes to the outer membrane surfaces in the blastocyst and is found predominantly in the nuclei of cleaving embryos (Pantaleon et al., 2001). GLUT-2 is active from the eight-cell stage onwards (Aghayan et al., 1992). GLUT-3 is active in four- to six-cell embryos, in which it is uniformly expressed, and in morulae and blastocysts (Hogan et al., 1991; Chi et al., 1993; Pantaleon et al., 1997; Moley et al., 1998; Leppens-Luisier et al., 2001), in which it localizes to the outside membranes, specifically to the apical region of the blastocyst (Pantaleon et al., 1997). GLUT-8 is expressed in blastocysts (Carayannopoulos et al., 2000). Once an embryo compacts at the 8-18-cell stage it has two sets of cells, those on the inside and those on the outside. It has been shown that two groups of glucose transport mechanisms are functional in both human and mouse morulae and blastocysts. The outside cells have a facilitative, phloretinsensitive mechanism and the inside cells have a sodiumdependent active transport mechanism (Chi et al., 1993). The facilitative mechanism is controlled by GLUT-3 (Pantaleon et al., 1997) and GLUT-8 (Carayannopoulos et al., 2000), and the function of these mechanisms is an essential step in blastocyst formation, independent of the presence of glucose and its metabolism, as can be shown by the formation of blastocysts in the absence of glucose (Brown and Whittingham, 1992; Scott and Whittingham, 1996). The expression and function of both facilitative, and later active, transport of glucose in preimplantation embryos is essential for both metabolism and development.

Different strains of mouse embryos react differently to the combined presence of glucose and inorganic phosphate (Chatot et al., 1990, 1994; Brown and Whittingham, 1992; Scott and Whittingham, 1996) or to different concentrations of these constituents (L. Scott and D. G. Whittingham, unpublished), with developmental blocks at various stages. It has been shown that oocytes and embryos exposed in vivo to altered glucose states in diabetic mice have poor developmental potential. Furthermore, these embryos have fewer GLUT-1, -2 and -3 proteins (Moley et al., 1998). It was hypothesized that pronuclear stage embryos of strains of mice that are sensitive to glucose and inorganic phosphate have either an overinduction of facilitative glucose transport when they are placed in culture or they loose the ability to control the uptake of glucose when isolated from the oviductal environment. In the present study, the interactions among glucose, facilitative uptake of glucose and inorganic phosphate in the developmental block at the two-cell stage, and continued development of three genetically distinct strains of mouse embryo were investigated using an inhibitor of facilitative glucose transporters.

\section{Materials and Methods}

\section{Animals}

Male and female $\mathrm{CF}-1$ and $\mathrm{CD}-1$ mice, male $\mathrm{C} 57 \mathrm{BI} / 6 \mathrm{NCr}$ mice and female $\mathrm{C} 3 \mathrm{H} / \mathrm{HeNCr}$ mice were purchased from Charles River Laboratories (Richmond, VA). All $\mathrm{F}_{1}$ hybrids were generated from the male $\mathrm{C} 57 \mathrm{BI} / 6 \mathrm{NCr}$ and female $\mathrm{C} 3 \mathrm{H} / \mathrm{HeNCr}$ mice. $\mathrm{CD} 1$ and $\mathrm{F}_{1}$ mice of 3.5-4.0 weeks of age were superovulated with 7.5 iu chorionic gonadotrophin (G-4877; Sigma Chemical Company, St Louis, MO) followed by 7.5 iu hCG (CG5; Sigma) $44-48$ h later, and were mated to proven stud males of the same strain. Eightto ten-week-old CF-1 female mice were superovulated using 10 iu chorionic gonadotrophin followed by 7.5 iu hCG. The mating of $\mathrm{F}_{1}(\mathrm{C} 3 \mathrm{H} / \mathrm{HeNCr} \times \mathrm{C} 57 \mathrm{Bl} / 6 \mathrm{NCr})$ mice generated $F_{2}$ embryos.

\section{Media}

All the culture media used have been described by Scott et al. (1993) and Scott and Whittingham (1996). The media consisted of a modified Earle's balanced salt solution without glucose or phosphate but with added EDTA $\left(0.11 \mathrm{mmol} \mathrm{I}^{-1}\right)$, pyruvate $\left(0.33 \mathrm{mmol} \mathrm{I}^{-1}\right)$ and glutamine $\left(1.0 \mathrm{mmol} \mathrm{I}^{-1}\right)$ as the basic medium (EMO). The basic medium was modified by the addition of $2.78 \mathrm{mmol}$ glucose $\mathrm{I}^{-1}$ (EMG) or $2.78 \mathrm{mmol}^{-}$glucose $\mathrm{I}^{-1}$ plus $1.32 \mathrm{mmol}$ inorganic phosphate $\mathrm{I}^{-1}$ as the sodium salt (EMGP). All media were made from stock solutions and supplemented with $3 \mathrm{mg}$ polyvinyl alcohol $\mathrm{ml}^{-1}$ (PVA) (P-8136; Sigma).

The glucose transporter inhibitor phloretin specifically inhibits the facilitative uptake of glucose in many types of cells (Lawrence et al., 1990) and in particular in preimplantation embryos (Gardner and Leese, 1988). Phloretin (P7912; Sigma) is insoluble in an aqueous solution, therefore dimethylsulphoxide (DMSO) (D-2650; Sigma) was used as a carrier. A stock solution of $27 \mathrm{mg}$ phloretin in $0.1 \mathrm{ml}$ DMSO was prepared and this solution was diluted to $1 \mathrm{ml}$ in $\mathrm{EMO}\left(25 \mathrm{mg} \mathrm{ml}^{-1}, 10.0 \mathrm{mmol} \mathrm{I}^{-1}\right)$. This solution was 
used to make up media containing various concentrations of phloretin from 0.005 to $1.0 \mathrm{mmol} \mathrm{I}^{-1}$ in EMG $(2.78 \mathrm{mmol}$

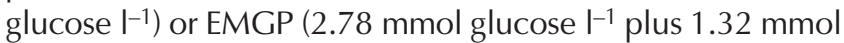
inorganic phosphate ${ }^{-1}$ ).

As DMSO was used as the carrier for the phloretin, control media were prepared using EMG plus DMSO at concentrations of $0.1 \%(\mathrm{v} / \mathrm{v})$ and $0.05 \%(\mathrm{v} / \mathrm{v})$ to test the effects of DMSO on the development of embryos in vitro. These concentrations were five and ten times greater, respectively, than the amount of DMSO added with phloretin to the culture medium.

\section{Embryo collection, culture and scoring}

All procedures have been described by Scott and Whittingham (1996). Female mice with vaginal plugs were killed at $18 \mathrm{~h}$ after hCG and the oviducts isolated into small drops of EMO under warmed equilibrated light mineral oil (0121-1; Fisher Scientific, Pittsburgh, PA). The cumulusoocyte complexes were released directly into EMO containing $0.2 \mathrm{mg}$ hyaluronidase $\mathrm{ml}^{-1}$ (H3506; Sigma) and the embryos freed by gentle pipetting with a pulled pipette. The embryos were washed through $3 \times 2 \mathrm{ml}$ rinses of EMO and then placed in groups of ten embryos per $10 \mu$ drop of the medium to which they were designated.

At 48, 72, 96 and $120 \mathrm{~h}$ after hCG $(30,54,78$ and $102 \mathrm{~h}$ of culture) the embryos were scored for stage of development using an inverted microscope with a heated stage and differential contrast optics at magnifications of $\times 310$ and $\times 520$, and a video recorder to minimize the time required for scoring. At each time point embryos had to be at the following minimum developmental stage to be scored as surviving: two-cell at $48 \mathrm{~h}$, four-cell at $72 \mathrm{~h}$, eightcell-morulae at 96 h, blastocysts at $120 \mathrm{~h}$. Embryos that had not reached these stages or were fragmenting or compacting with too few cells $(<8)$ were scored as non-survivors (Scott and Whittingham, 1996).

\section{Statistical analysis}

Means, standard errors, ANOVA and chi-squared analysis were performed using Statistix 4.0 (Analytical Software, St Pauls, MN).

\section{Results}

\section{Control cultures}

Embryos from the three strains were grown in EMO, EMG and EMGP from the one-cell to the blastocyst stage (120 $\mathrm{h}$ after hCG; $102 \mathrm{~h}$ of culture) and development was recorded at 72, 96 and $120 \mathrm{~h}$ after hCG. Twenty embryos per type of medium were used in each replicate and the experiments were repeated five times concurrently with the early development studies with phloretin (see below). CF-1 embryos showed equivalent development in $\mathrm{EMO}$ and EMG, but no development in EMGP (Fig. 1). CD-1 embryos showed the same developmental pattern with minimum development in EMGP (Fig. 1). $F_{2}$ embryos developed equally as well in all three media (Fig. 1). These data indicate that CF-1 and CD-1 embryos, but not $\mathrm{F}_{2}$ embryos, are sensitive to the combined presence of glucose and inorganic phosphate but not glucose alone, as shown by Scott and Whittingham (1996).

\section{DMSO controls}

Control experiments were carried out to test for any negative effects of the DMSO used to solublize the phloretin. Pronuclear and two-cell CD-1 embryos were cultured in modified EMO containing $0.5 \mathrm{mmol}$ glucose $\mathrm{I}^{-1}$ plus $0.1 \%$ or $0.05 \%$ (v/v) DMSO.

For pronuclear CD-1 embryos, modified EMO plus $0.05 \%$ or $0.1 \%(\mathrm{v} / \mathrm{v})$ DMSO resulted in $76 \%(23 / 30)$ and $73 \%$ (22/30) fully expanded blastocysts at $120 \mathrm{~h}$ after hCG, respectively. The development of two-cell CD-1 embryos in modified EMO plus $0.05 \%$ or $0.1 \%(\mathrm{v} / \mathrm{v})$ DMSO resulted in $80 \%(24 / 30)$ and $87 \%(26 / 30)$ expanded blastocyst formation, respectively. These results indicate that the DMSO was not toxic to the embryos.

\section{Inhibition of facilitated glucose transport and development}

Phloretin treatments. Initially, increasing concentrations of phloretin in EMGP were tested with $F_{2}$ embryos. The concentrations of phloretin chosen were 0.01, 0.05, 1.0 and $1.0 \mathrm{mmol} \mathrm{I}^{-1}$ based on those used by Gardner and Leese (1988). Concentrations of $1.0,0.1$ and $0.05 \mathrm{mmol}$ phloretin $\mathrm{I}^{-1}$ in continuous culture from the one-cell stage were toxic to $F_{2}$ embryos (data not shown). With a concentration of $1.0 \mathrm{mmol}$ phloretin $\mathrm{I}^{-1}$ the embryos lysed, and at 0.1 and $0.05 \mathrm{mmol} \mathrm{I}^{-1}$ the first cleavage division was inhibited or the $F_{2}$ embryos began to fragment. Thus, concentrations of 0.005 and $0.01 \mathrm{mmol}^{2}$ phloretin $\mathrm{I}^{-1}$ were used in the rest of this study.

Early development. Pronuclear CF-1, CD-1 and $\mathrm{F}_{2}$ embryos were cultured in EMG or EMGP with 0.01 or 0.005 mmol phloretin $\mathrm{I}^{-1}$ to investigate the role that facilitative glucose transport plays in embryo development. Zygotes were isolated at $18 \mathrm{~h}$ after hCG and incubated in phloretin for 4, 6, 30 (48 h after hCG) or 54 (72 h after hCG) h and then washed through $3 \times 2 \mathrm{ml}$ rinses of EMG or EMGP before being placed in $10 \mu \mathrm{l}$ drops of EMG or EMGP for continued culture. Embryo development was scored at 72, 96 and $120 \mathrm{~h}$ after hCG.

When CF-1 zygotes were incubated in EMG with either concentration of phloretin for 4 or $6 \mathrm{~h}$ and returned to EMG there was a significant reduction in the number of embryos progressing to the eight-cell stage (72 h after hCG) (Table 1) compared with controls (Fig. $1 ; 53 \%$ and $55 \%$ versus $95 \%$; $P<0.01)$. In the embryos that did not progress to the eightcell stage, development was blocked at the two-cell stage. Most of the embryos that cleaved to the four-cell stage formed blastocysts, but the proportion was reduced compared with that for controls $(42 \%$ and $45 \%$ versus $75 \%$; 


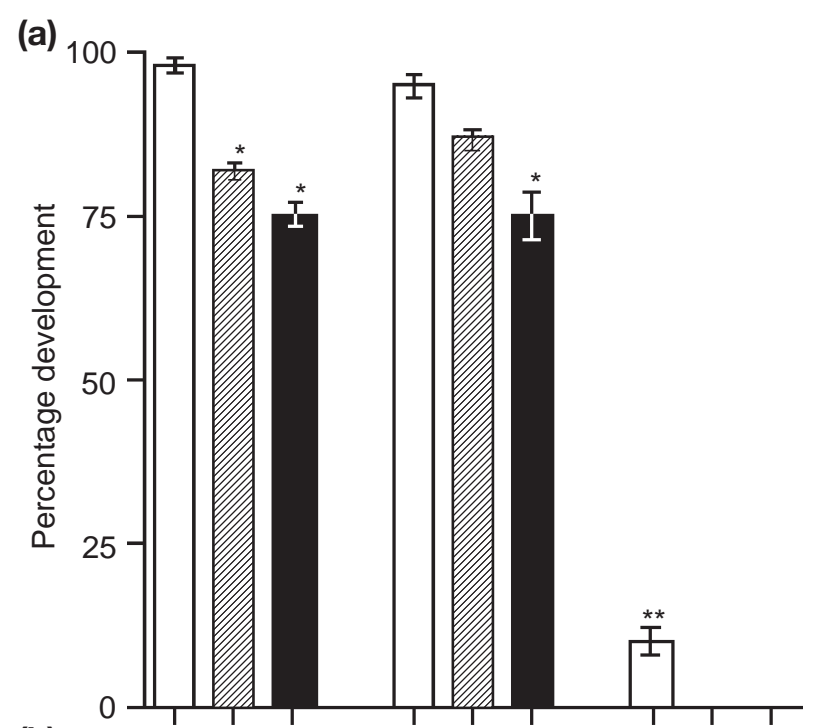

(b)

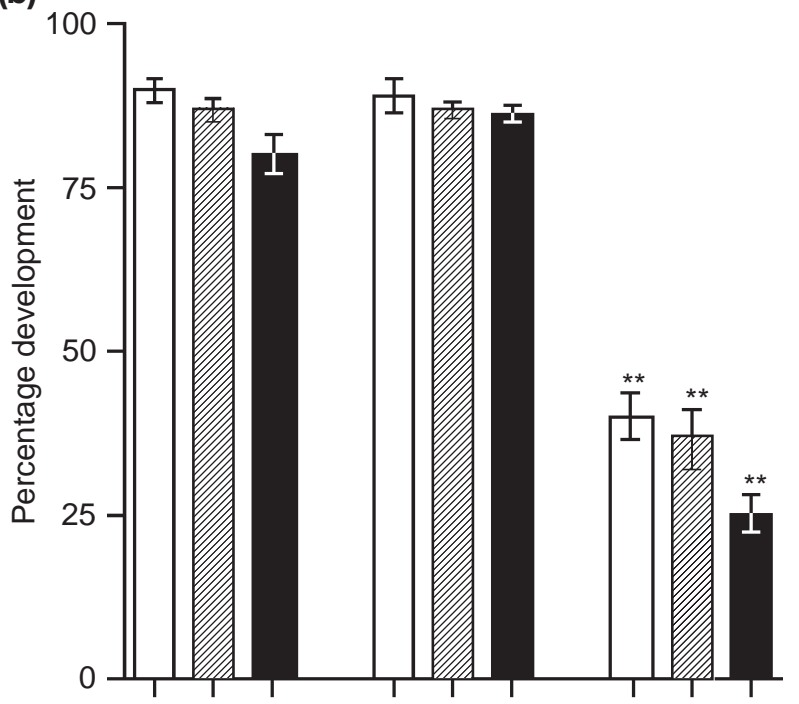

(c)

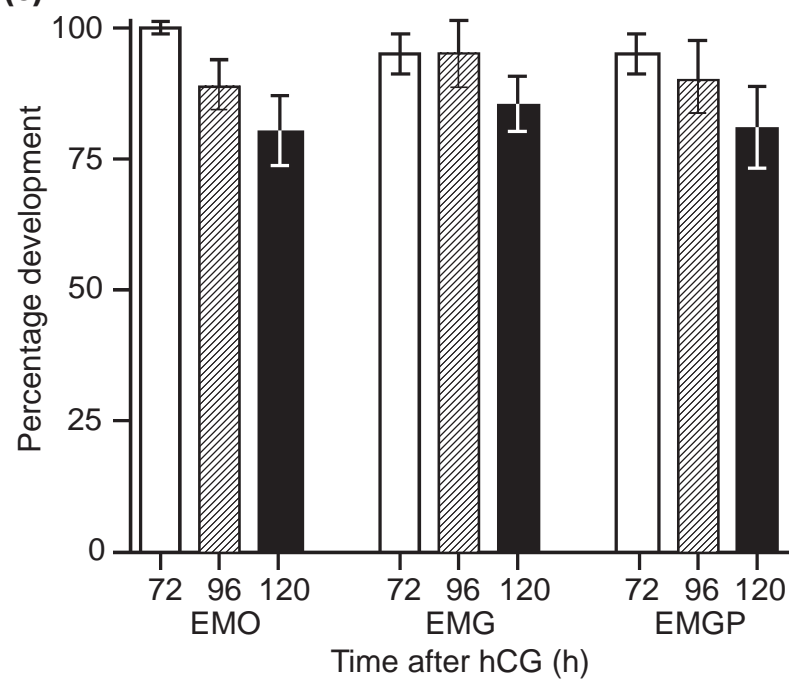

Fig. 1. Control data: development of pronucleate (a) CF-1, (b) CD-1 or (c) $F_{2}$ mouse embryos in three different media over $106 \mathrm{~h}$ of
$P<0.01)$ or when the embryos were grown without glucose (EMO, 75\%; $P<0.01)$.

When CF-1 embryos were grown in EMG plus phloretin from the one- to the two-cell stage (18-48 h after hCG, $30 \mathrm{~h}$ of culture), and then moved to EMG, only one-third progressed beyond the four-cell stage. In the remaining embryos, development was blocked at the two-cell stage. Only half of the eight-cell embryos progressed to the blastocyst stage in either 0.01 or $0.005 \mathrm{mmol}^{\text {phloretin } \mathrm{I}^{-1}}$ $(P<0.001$ compared with controls; $17 \%$ and $22 \%$ versus $75 \%)$.

When the embryos were grown in either 0.01 or

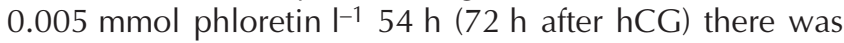
a reduction in embryo development compared with that in control cultures at $72 \mathrm{~h}(68 \%$ and $65 \%$ versus $95 \%$; $P<0.05)$. When the embryos were moved from $0.01 \mathrm{mmol}$ phloretin $\mathrm{I}^{-1}$ to EMG at $72 \mathrm{~h}$, half of the embryos arrested or became atretic, and there was a significant reduction in blastocyst development, compared with controls $(28 \%$ versus $75 \% ; P<0.01)$. When the embryos were moved

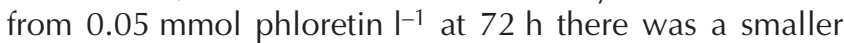
but significant reduction in blastocyst development $(47 \%$ versus $75 \% ; P<0.05)$.

Culture in EMGP with phloretin for 4 or $6 \mathrm{~h}$ followed by culture in EMGP resulted in minimum development to the four-cell stage and no blastocyst development, which was not different from the control results. After $30 \mathrm{~h}$ of incubation in either 0.01 or 0.005 mmol phloretin $\mathrm{I}^{-1}$, significantly more embryos developed to the eight-cell-morula stage compared with controls $(37 \%$ and $49 \%$ versus $10 \% ; P<0.001)$ but there was minimum development to the blastocyst stage. When CF-1 embryos were cultured in either 0.01 or $0.005 \mathrm{mmol}^{2}$ phloretin $\mathrm{I}^{-1}$ in EMGP for $54 \mathrm{~h}$ (72 $\mathrm{h}$ after hCG) and returned to EMGP there was a significant increase in development to the blastocyst stage compared with that in control embryos cultured in EMGP $(52 \%$ and $48 \%$ versus $0 \% ; P<0.001)$. Although the extent of blastocyst formation was not as great as that seen with EMO $(75 \%)$ or EMG (75\%), the result was still significant $(P<0.01)$.

Culturing CD-1 embryos (Table 2) for 4 or $6 \mathrm{~h}$ in either concentration of phloretin in EMG resulted in a halving of blastocyst development (37-48\% blastocyst development) compared with that in control cultures $(86 \%$ blastocyst development) $(P<0.01)$. When embryos were cultured to the two-cell stage, $30 \mathrm{~h}$ of culture, there was significant reduction in overall development and minimum blastocyst development $(13 \%$ and $22 \%$ versus $86 \% ; P<0.001)$. After

culture (120 h after hCG). Development was scored at 72 ( $\square$ ), 96 (ש) and $120 \mathrm{~h}(\boldsymbol{\square})$ after hCG. EMO: Earle's balanced salt solution with added EDTA $\left(0.11 \mathrm{mmol} \mathrm{I}^{-1}\right)$, pyruvate $\left(0.33 \mathrm{mmol} \mathrm{I}^{-1}\right)$ and glutamine $\left(1.0 \mathrm{mmol} \mathrm{I}^{-1}\right)$. EMG and EMGP: EMO modified by the addition of $2.78 \mathrm{mmol}_{\text {glucose }}^{-1}$ (EMG) or $2.78 \mathrm{mmol}$

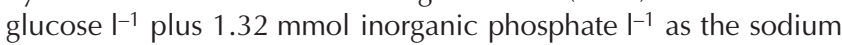
salt (EMGP). Data represent the mean of five repeated experiments with 20 embryos per replicate; total of 100 embryos in each media. $* P<0.01$ versus EMO; ${ }^{* *} P<0.001$ versus EMO. 
Table 1. Survival of pronuclear CF-1 mouse embryos to the blastocyst stage ( $120 \mathrm{~h}$ after hCG) after culture in EMG or EMGP medium plus 0.01 or 0.005 mmol phloretin $\mathrm{I}^{-1}$, beginning at the pronucleate stage, for 4, 6, 30 or $54 \mathrm{~h}$ followed by culture in EMG or EMGP medium

\begin{tabular}{|c|c|c|c|c|c|c|}
\hline \multirow[b]{2}{*}{$\begin{array}{l}\text { Time of } \\
\text { exposure } \\
\text { (h) }\end{array}$} & \multicolumn{3}{|c|}{$\mathrm{EMG}+0.01 \mathrm{mmol}$ phloretin $\mathrm{I}^{-1}$} & \multicolumn{3}{|c|}{$\mathrm{EMG}+0.005 \mathrm{mmol}$ phloretin $\mathrm{I}^{-1}$} \\
\hline & $\begin{array}{c}72 \mathrm{~h} \\
(\% \geqslant \\
\text { four-cell })\end{array}$ & $\begin{array}{c}96 \mathrm{~h} \\
(\% \geqslant \\
\text { morula })\end{array}$ & $\begin{array}{c}120 \mathrm{~h} \\
(\%> \\
\text { blastocyst })\end{array}$ & $\begin{array}{c}\quad 72 \mathrm{~h} \\
(\% \geqslant \\
\text { four-cell })\end{array}$ & $\begin{array}{c}96 \mathrm{~h} \\
(\% \geqslant \\
\text { morula) }\end{array}$ & $\begin{array}{c}120 \mathrm{~h} \\
(\%> \\
\text { blastocyst })\end{array}$ \\
\hline 4 & $53(3.9)^{* *}$ & $50(5.3)$ & $42(3.6)^{* *}$ & $68(1.0)$ & $58(1.2)$ & $45(0.5)^{* *}$ \\
\hline 6 & $55(4.1)^{* *}$ & $50(3.9)$ & $48(2.4)^{* *}$ & $57(2.1)$ & $42(2.2)$ & $38(4.6)^{* *}$ \\
\hline 30 & $34(2.9)^{* *}$ & $22(4.7)$ & $17(4.8)^{* * *}$ & $41(0.8)$ & $30(1.7)$ & $22(3.4)^{* * *}$ \\
\hline \multirow[t]{2}{*}{54} & $68(3.7)^{*}$ & $36(3.5)$ & $28(2.4)^{* *}$ & $65(2.7) *$ & $52(1.9)$ & $47(4.0)^{* *}$ \\
\hline & \multicolumn{3}{|c|}{$\mathrm{EMGP}+0.01 \mathrm{mmol}$ phloretin $\mathrm{I}^{-1}$} & \multicolumn{3}{|c|}{$\mathrm{EMGP}+0.005 \mathrm{mmol}$ phloretin $\mathrm{I}^{-1}$} \\
\hline $\begin{array}{l}\text { Time of } \\
\text { exposure } \\
\text { (h) }\end{array}$ & $\begin{array}{c}72 \mathrm{~h} \\
(\% \geqslant \\
\text { four-cell })\end{array}$ & $\begin{array}{c}96 \mathrm{~h} \\
(\% \geqslant \\
\text { morula })\end{array}$ & $\begin{array}{c}120 \mathrm{~h} \\
(\%> \\
\text { blastocyst })\end{array}$ & $\begin{array}{c}\quad 72 \mathrm{~h} \\
(\% \geqslant \\
\text { four-cell })\end{array}$ & $\begin{array}{c}96 \mathrm{~h} \\
(\% \geqslant \\
\text { morula })\end{array}$ & $\begin{array}{c}120 \mathrm{~h} \\
(\%> \\
\text { blastocyst })\end{array}$ \\
\hline 4 & $5(0.9)$ & 0 & 0 & 0 & 0 & 0 \\
\hline 6 & $17(1.7)$ & $14(1.9)$ & 0 & $12(1.1)$ & $8(0.3)$ & 0 \\
\hline 30 & $37(2.3)^{* * *}$ & $12(1.5)$ & $5(0.8)^{* *}$ & $49(3.7)^{* * *}$ & $21(2.3)$ & $7(1.8)$ \\
\hline 54 & $63(3.0)^{* * *}$ & $58(3.2)$ & $52(3.4)^{* *}$ & $71(2.1)^{* * *}$ & $51(4.0)$ & $48(2.8)^{* *}$ \\
\hline
\end{tabular}

Data represent the mean of five experiments with 20 embryos per group per replicate; total 100 embryos per treatment. Values in parentheses: (SEM) at $120 \mathrm{~h}$ after hCG.

EMG and EMGP: Earle's balanced salt solution with added EDTA $\left(0.11 \mathrm{mmol}^{-1}\right)$, pyruvate $\left(0.33 \mathrm{mmol} \mathrm{I}^{-1}\right)$ and glutamine $\left(1.0 \mathrm{mmol} \mathrm{I}^{-1}\right)$ and modified by the addition of $2.78 \mathrm{mmol}$ glucose $\mathrm{I}^{-1}$ (EMG) or $2.78 \mathrm{mmol}$ glucose $\mathrm{I}^{-1}$ plus

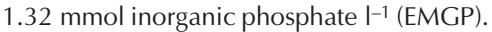

Asterisks indicate result is significantly different from controls: ${ }^{*} P<0.05$; ${ }^{* *} P<0.01 ;{ }^{* * *} P<0.001$.

$54 \mathrm{~h}$ in phloretin followed by culture in EMG, development was equivalent to that seen in control cultures and there was no difference in results between the two concentrations of phloretin.

When CD-1 embryos were cultured in EMGP with phloretin for 4, 6 or $30 \mathrm{~h}$ followed by culture in EMGP there was no difference in development compared with that in control cultures (25\%; Fig. 1), and development was significantly reduced compared with that obtained after culture in EMO (80\%) or EMG (86\%) (no inorganic phosphate). When the time in phloretin was increased to $72 \mathrm{~h}$ after hCG $(54 \mathrm{~h}$ of culture), development was equivalent to that in cultures without inorganic phosphate $(82 \%$ and $73 \%$ versus $80 \%$ and $86 \%)$, and significantly greater than that in EMGP $(82 \%$ and $73 \%$ versus $25 \% ; P<0.001)$. There was no difference in results between the two concentrations of phloretin.

$F_{2}$ embryos appeared to show no response to phloretin: embryo development was equivalent in all systems and was not different from that in control cultures (data not shown).

Later development. CF-1, CD-1 and $\mathrm{F}_{2}$ embryos were cultured in EMO for 30 or $54 \mathrm{~h}(48$ and $72 \mathrm{~h}$ after hCG, respectively) and then placed in EMGP containing 0.01 or $0.005 \mathrm{mmol}$ phloretin $\mathrm{I}^{-1}$ for further culture to $96 \mathrm{~h}$ after hCG, to study the importance of facilitative glucose transport at later stages of embryo development. At $96 \mathrm{~h}$ after hCG, the embryos were washed through $3 \times 2 \mathrm{ml}$ rinses of EMGP and cultured in EMGP. The total number of expanded blastocysts at $120 \mathrm{~h}$ after hCG was recorded and compared with that in continuous cultures (Fig. 1). All experiments were repeated five times with 20 embryos per group in each experiment giving a total of 100 embryos per treatment. The results are summarized (Fig. 2).

When CF-1 embryos were grown from the pronuclear to the two-cell stage in EMO followed by culture in EMGP plus 0.01 or $0.005 \mathrm{mmol}$ phloretin $\mathrm{I}^{-1}$ for a further $48 \mathrm{~h}(96 \mathrm{~h}$ after hCG) and then moved into EMGP, some blastocyst formation was observed $\left(17 \%\right.$ in $0.01 \mathrm{mmol}$ phloretin $\mathrm{I}^{-1}$ and $28 \%$ in 0.005 mmol phloretin $\mathrm{I}^{-1}$ ). The extent of blastocyst formation was significantly lower than the percentage survival obtained with EMO and EMG $(75 \%$ and $76 \%$, respectively; $P<0.01$; Fig. 1). When the embryos were cultured in EMO from the pronuclear stage until $72 \mathrm{~h}$ after hCG and then moved into EMGP plus phloretin for $24 \mathrm{~h}$, followed by culture in EMGP, the percentage blastocyst formation was equivalent to that obtained with culture in EMG (62\% and $70 \%$ versus $75 \%)$. The detrimental effects of glucose combined with inorganic phosphate were negated.

When pronuclear CD-1 embryos were cultured in EMO to the two- to four-cell stage ( $48 \mathrm{~h}$ after hCG) followed by 
Table 2. Survival of pronuclear CD-1 mouse embryos to the blastocyst stage ( $120 \mathrm{~h}$ after hCG) after

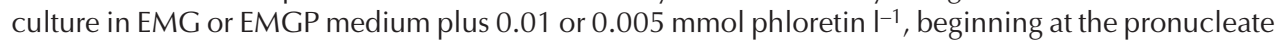
stage, for 4, 6, 30 or $54 \mathrm{~h}$ followed by culture in EMG or EMGP medium

\begin{tabular}{|c|c|c|c|c|c|c|}
\hline \multirow[b]{2}{*}{$\begin{array}{l}\text { Time of } \\
\text { exposure } \\
\text { (h) }\end{array}$} & \multicolumn{3}{|c|}{$\mathrm{EMG}+0.01 \mathrm{mmol}$ phloretin $\mathrm{I}^{-1}$} & \multicolumn{3}{|c|}{$\mathrm{EMG}+0.005 \mathrm{mmol}$ phloretin $\mathrm{I}^{-1}$} \\
\hline & $\begin{array}{c}72 \mathrm{~h} \\
(\% \geqslant \\
\text { four-cell })\end{array}$ & $\begin{array}{c}96 \mathrm{~h} \\
(\% \geqslant \\
\text { morula) }\end{array}$ & $\begin{array}{c}120 \mathrm{~h} \\
(\%> \\
\text { blastocyst })\end{array}$ & $\begin{array}{c}72 \mathrm{~h} \\
(\% \geqslant \\
\text { four-cell })\end{array}$ & $\begin{array}{c}96 \mathrm{~h} \\
(\% \geqslant \\
\text { morula })\end{array}$ & $\begin{array}{c}120 \mathrm{~h} \\
(\%> \\
\text { blastocyst })\end{array}$ \\
\hline 4 & $60(0.8)$ & $47(1.5)$ & $45(4.0)^{* *}$ & $51(0.9)$ & $50(3.2)$ & $48(2.4)^{* *}$ \\
\hline 6 & $68(1.1)$ & $52(2.3)$ & $42(2.4)^{* *}$ & $52(1.0)$ & $41(2.5)$ & $37(3.4)^{* *}$ \\
\hline 30 & $23(0.6)$ & $14(2.7)$ & $13(3.4)^{* * *}$ & $32(0.7)$ & $28(2.8)$ & $22(2.8)^{* * *}$ \\
\hline \multirow[t]{2}{*}{54} & $82(1.4)$ & $78(3.9)$ & $67(2.4)$ & $91(1.6)$ & $78(3.7)$ & $75(4.0)$ \\
\hline & \multicolumn{3}{|c|}{ 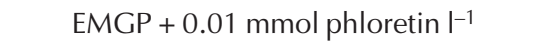 } & \multicolumn{3}{|c|}{$\mathrm{EMGP}+0.005 \mathrm{mmol}$ phloretin $\mathrm{I}^{-1}$} \\
\hline $\begin{array}{l}\text { Time of } \\
\text { exposure } \\
\text { (h) }\end{array}$ & $\begin{array}{c}72 \mathrm{~h} \\
(\% \geqslant \\
\text { four-cell })\end{array}$ & $\begin{array}{c}96 \mathrm{~h} \\
(\% \geqslant \\
\text { morula) }\end{array}$ & $\begin{array}{c}120 \mathrm{~h} \\
(\%> \\
\text { blastocyst })\end{array}$ & $\begin{array}{c}72 \mathrm{~h} \\
(\% \geqslant \\
\text { four-cell })\end{array}$ & $\begin{array}{c}96 \mathrm{~h} \\
(\% \geqslant \\
\text { morula })\end{array}$ & $\begin{array}{c}120 \mathrm{~h} \\
(\%> \\
\text { blatocyst })\end{array}$ \\
\hline 4 & $27(0.7)$ & $20(3.2)$ & $18(4.3)$ & $18(5.6)$ & $17(4.7)$ & $12(2.4)$ \\
\hline 6 & $31(1.6)$ & $25(1.8)$ & $23(2.4)$ & $22(3.9)$ & $19(5.1)$ & $18(4.5)$ \\
\hline 30 & $28(2.0)$ & $28(3.0)$ & $25(1.0)$ & $41(2.8)$ & $37(3.9)$ & $30(4.0)$ \\
\hline 54 & $92(1.8)$ & $89(2.7)$ & $82(2.8)^{* * *}$ & $83(1.8)$ & $80(3.0)$ & $73(2.8)^{* * *}$ \\
\hline
\end{tabular}

Data represent the mean of five experiments with 20 embryos per group per replicate; total 100 embryos per treatment. Values in parentheses: (SEM) at $120 \mathrm{~h}$ after hCG.

EMG and EMGP: Earle's balanced salt solution with added EDTA $\left(0.11 \mathrm{mmol}^{-1}\right)$, pyruvate $\left(0.33 \mathrm{mmol}^{-1}\right)$ and

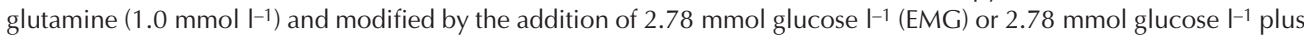

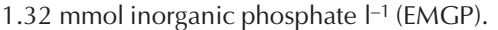

Asterisks indicate result is significantly different from controls: ${ }^{*} P<0.05 ;{ }^{* *} P<0.01 ;{ }^{* * *} P<0.001$.

culture in EMGP plus phloretin until $96 \mathrm{~h}$ after hCG and then moved to EMGP, the extent of blastocyst formation at $120 \mathrm{~h}$ after hCG was no different from that obtained from continuous culture in EMGP (34\% and $48 \%$ versus $25 \%$, Fig. 1), but was lower than that with EMO $(80 \% ; P<0.005)$ and EMG $(86 \% ; P<0.001)$. When embryos were moved to EMGP plus phloretin at $72 \mathrm{~h}$ after hCG and then to EMGP at $96 \mathrm{~h}$ after hCG, the percentage blastocyst formation at $120 \mathrm{~h}(74 \%$ and $81 \%)$ was the equivalent to that in continuous culture in EMO (80\%) or EMG (86\%). The phloretin removed the glucose-inorganic phosphate effects.

The survival of $F_{2}$ embryos was equivalent in all systems except that there was a small but significant $(P<0.05)$ increase in development when $F_{2}$ embryos were cultured in EMO for $48 \mathrm{~h}$ followed EMGP plus phloretin.

\section{Viability of phloretin-treated embryos}

A further set of CF-1 and CD-1 embryos was cultured in EMGP containing $0.005 \mathrm{mmol}$ phloretin $\mathrm{I}^{-1}$ for $72 \mathrm{~h}$ and then moved to EMGP. The resulting blastocysts were transferred to pseudopregnant females. Embryos not exposed to phloretin, but cultured in EMO for the same duration, were transferred to the contralateral horn of the pseudopregnant host. The contralateral horn was chosen in an attempt to negate any effects the recipient may have had on implantation. It has been shown that embryos from all three strains result in viable offspring when cultured in $\mathrm{EMO}$ or EMG, and CD-1 and $F_{2}$ when cultured in EMGP (Scott and Whittingham, 1996).

A total of 30 CD-1 and 30 CF-1 embryos cultured in EMO and 30 CD-1 and 30 CF-1 embryos cultured in EMGP

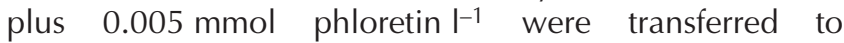
pseudopregnant females on day 3 or day 4 of pseudopregnancy. Six experimental CF-1 embryos and six control embryos were transferred to each of five recipient females, and five experimental and five control CD-1 embryos to each of six recipient females. The embryos were at the morula and blastocyst stages. Both control and test embryos of the same strain were transferred to the contralateral horn of each female.

Of the 11 pseudopregnant females used, eight became pregnant $(73 \%), 5 / 6$ carrying CD-1 embryos and 3/5 carrying CF-1 embryos. At day 18 of gestation the females were killed and the numbers of implantation sites and live fetuses were scored.

A total of 18 CD-1 control embryos implanted $(72 \%$ of the embryos transferred to pregnant females) and 15 phloretin-treated embryos implanted (60\%). The CF-1 embryos had a lower rate of implantation, but within the strains there were no differences between controls and test groups. Nine control CF-1 embryos implanted $(60 \%$ of 
(a)

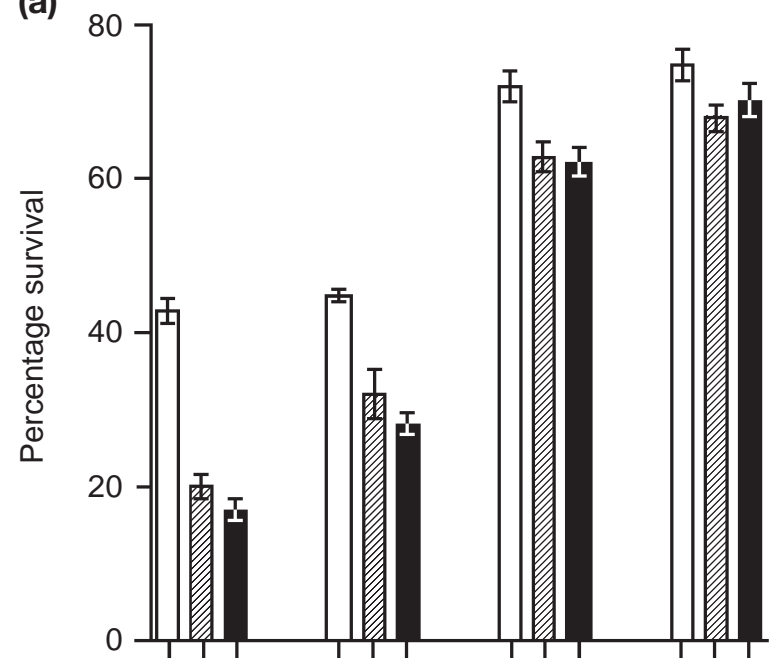

(b)

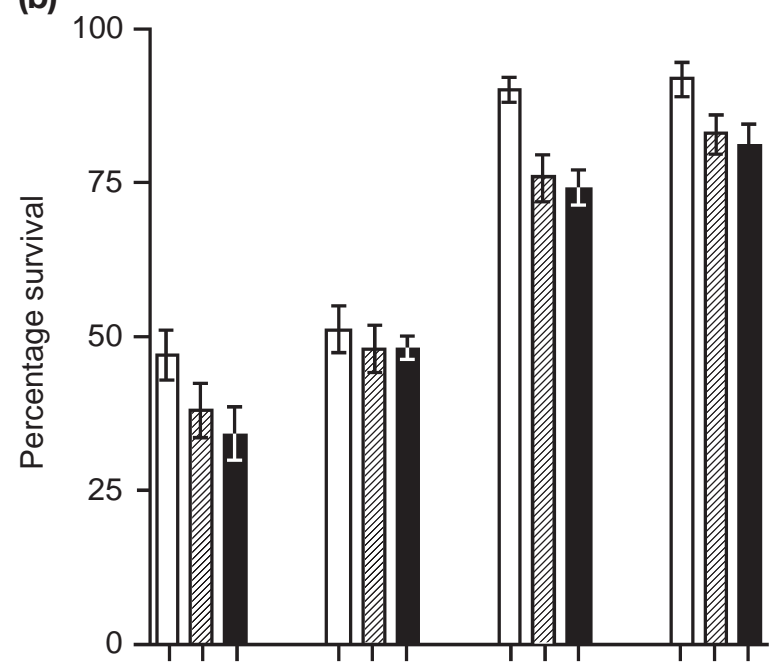

(c)

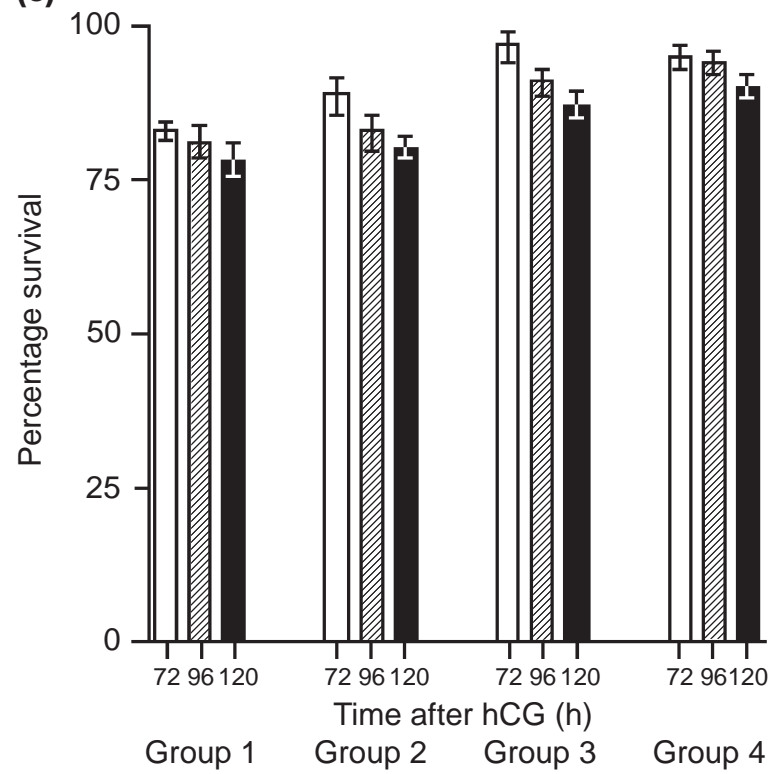

Fig. 2. Survival of (a) CF-1, (b) CD-1 and (c) $F_{2}$ mouse embryos in different media containing phloretin over $106 \mathrm{~h}$ of culture. Survival those transferred to pregnant females) and eight experimental embryos implanted (53\%). These results were not statistically different and indicate that the embryos grown without glucose or in the presence of phloretin were viable.

\section{Discussion}

The data presented here demonstrate that, in embryo strains that would normally show developmental arrest in medium containing glucose and inorganic phosphate (Scott and Whittingham, 1996), the inhibition of facilitative glucose transport by phloretin before the morula stage can overcome the developmental block. There was no effect on $\mathrm{F}_{2}$ embryos, which do not show glucose-inorganic phosphate-mediated blocks in development. Furthermore, embryos cultured in the presence of the transporter inhibitor phloretin were viable when transferred to pseudopregnant females. These results imply that glucose transport is involved in the glucose-inorganic phosphate-mediated developmental block in mouse embryos, as reported by Leppens-Luisier et al. (2001), and that this involvement is dependent on embryo stage and strain.

The results reported here on inhibition of facilitative glucose uptake in the three strains of embryos demonstrate that the glucose-inorganic phosphate-mediated block at the two-cell stage and decreased development can be overcome, at least in part, when the facilitative uptake of glucose is inhibited. However, the mechanisms by which this occurs appear to be different in the three strains and is related to the developmental stage of the embryos and the medium composition.

The development of CF-1 and CD-1 embryos is not affected by glucose at a concentration of $2.78 \mathrm{mmol} \mathrm{I}^{-1}$ if there is no inorganic phosphate in the medium, but development is inhibited when inorganic phosphate is present (Scott and Whittingham, 1996). When facilitated glucose transport was inhibited to at least the eightcell-morula-stage, development was not affected in medium containing both glucose and inorganic phosphate, indicating that the inhibition of facilitative glucose uptake can overcome the developmental block. When the inhibition of glucose transport was removed before the eight-cell-morula stage, CF-1 embryos stopped growing completely and CD-1 embryos showed minimum

was scored at $72(\square), 96(\mathbb{Q})$ and $120 \mathrm{~h}(\boldsymbol{\square}) \pm$ SEM after hCG. All embryos were cultured in EMO (Earle's balanced salt solution with

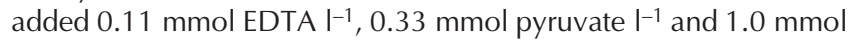
glutamine $\mathrm{I}^{-1}$ ) for the initial period and moved to EMGP (EMO with

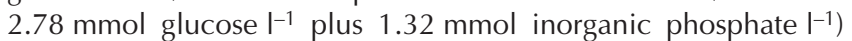
with phloretin for 24 or $48 \mathrm{~h}$ and then cultured in EMGP. Group 1:

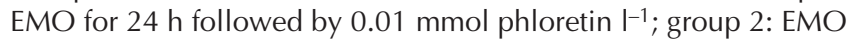
for $24 \mathrm{~h}$ followed by $0.005 \mathrm{mmol}$ phloretin $\mathrm{I}^{-1}$; group 3: EMO for $48 \mathrm{~h}$ followed by $0.01 \mathrm{mmol}$ phloretin $\mathrm{I}^{-1}$; group 4 : EMO for $48 \mathrm{~h}$ followed by $0.05 \mathrm{mmol}$ phloretin $\mathrm{I}^{-1}$. Data represent the mean of five repeated experiments with 20 embryos per replicate; total of 100 embryos per treatment. 
development. These findings indicate that the transporters are operational from early in development and begin functioning when the inhibitor is removed from the culture system. Both CF-1 and CD-1 embryos suffer the same shock at early stages of development when moved from glucoseand inorganic phosphate-free medium to medium with either glucose or both constituents before the stage at which they can metabolize glucose fully (L. Scott and D. G. Whittingham, unpublished). The experiments in which the embryos were cultured without glucose or inorganic phosphate followed by culture with both constituents plus phloretin before the morula stage confirm this contention. $\mathrm{F}_{2}$ embryos are not affected by inorganic phosphate and glucose and showed no response to the transporter inhibitor at any stage in development.

The developmental blocks shown in vitro by embryos from some mouse strains can be explained by the fact that mouse embryos cannot utilize glucose in glycolysis for energy production during the first few cleavage divisions. However, mouse embryos do take up glucose in both a passive and facilitative manner from the one-cell stage onwards in vitro, when placed in medium containing 1-5 mmol glucose ${ }^{-1}$ (Barbehenn et al., 1974, 1978; Gardner and Leese, 1988; Gardner and Sakkas, 1993). Facilitative glucose uptake is mediated by a family of glucose transporters, the members of which are a highly homologous group of membrane-associated proteins (Bell et al., 1990; Kasanicki and Pilch, 1990). Five isoforms have been described to date, each of which is found predominantly in certain types of tissue. The glucose transporter that is present in most tissues is GLUT-1. Fetal tissue relies predominantly on GLUT-1 for all glucose uptake. The work done by Gardner and Leese (1988) and more recently by Leppens-Luisier et al. (2001) indicates that mouse embryos contain at least one type of facilitative glucose transporter, which is operational from the one-cell stage onwards. It has also been shown at both a gene expression (Hogan et al., 1991) and a protein level (Aghayan et al., 1992) that mouse oocytes and mouse embryos at all the preimplantation stages of development contain GLUT-1 (Pantaleon et al., 1997, 2001; Carayannopoulos et al., 2000; Leppens-Luisier et al., 2001).

At the blastocyst stage, there is a form of active sodiumdependent glucose transport, which is localized in the inner cells, presumably for rapid transport of glucose to the inner part of the embryo (Chi et al., 1993; Carayannopoulos et al., 2000; Ibberson et al., 2000). Another form of active glucose transport is present between the two- and four-cell stages in mouse embryos, as shown by inhibition with phlorazin, an inhibitor of sodium-dependent glucose transport (LeppensLuisier et al., 2001). Even in the presence of phloretin, active transport of glucose occurs for this brief period. In the absence of inorganic phosphate, the small amount of glucose entering the embryos would enhance development, similar to results from pulse experiments in which both CF-1 and CD-1 one-cell embryos benefit from exposure to

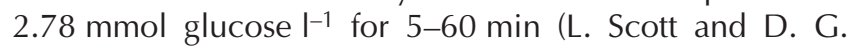
Whittingham, unpublished).
Although GLUT-1 is the most common facilitative transporter for glucose and is expressed in all stages of embryo development, it is not localized on the cell surface in mouse embryos until compaction (Pantaleon et al., 2001), at which stage the embryo begins to use glucose for metabolism. This is also true of the GLUT-2 and GLUT-3 isoforms, which appear as cleavage progresses (Hogan et al., 1991; Aghayan et al., 1992; Chi et al., 1993; Pantaleon et al., 1997; Moley et al., 1998; Leppens-Luisier et al., 2001). In the present study, the phloretin may have had an effect on any of these isoforms as it was introduced after the two-cell stage but was removed at or before compaction, when the embryo requires glucose.

Leppens-Luisier et al. (2001) used a system of continuous culture to the blastocyst stage to examine the role and transport of glucose. Similar to the findings of the present study and those of others (Chatot et al., 1990; Brown and Whittingham, 1992; Scott and Whittingham, 1996), the presence of glucose and inorganic phosphate inhibited development to the blastocyst stage. When glucose was replaced by a non-metabolizable analogue, 3-0methylglucose, there was no inhibition, the equivalent of having no glucose present. When the analogue replacing glucose was a form that could be taken up and phosphorylated (2-deoxyglucose), development was inhibited, indicating that both glucose uptake and energy depletion from phosphorylation are involved in the developmental blocks and delays observed in vitro with glucose. The inhibitor phloretin had no effect on the early cleavage stages but did inhibit the morula-blastocyst transition. This would presumably be due to the need for glucose for this transition when inorganic phosphate is present (Scott and Whittingham, 1996) as shown by Brown and Whittingham (1992) and Chatot et al. (1994). This finding is in contrast to the current study in which the presence of phloretin did not affect the morula-blastocyst transition. In the study of Scott and Whittingham (1996), inhibition of the morula-blastocyst transition was overcome when no inorganic phosphate was present in the medium. It was speculated that the inhibition occurred at pyruvate dehydrogenase, the activity of which is depressed with high concentrations of inorganic phosphate. In the present study, the embryos were always exposed to some glucose, which may have been sufficient to enable the transition to occur. Furthermore, the phloretin was removed at or before $72 \mathrm{~h}$ after hCG, when the transition would be occurring, and at which stage mouse embryos begin to metabolize glucose actively (Gardner and Leese, 1988; Leese, 1991; Gardner and Sakkas, 1993; Scott and Whittingham, 1996). The purpose of the current study was to examine the role of facilitative glucose transport in the glucose-inorganic phosphate-mediated developmental blocks. As the introduction of either or both constituent after compaction did not affect development, and low concentrations of glucose without inorganic phosphate enhanced development (L. Scott and D. G. Whittingham, unpublished), continuing transport inhibition after compaction was considered necessary. 
The exact mechanism of action of the glucose transporters has not been clearly elucidated. Phosphorylation of glucose, or its analogues (Leppens-Luisier et al., 2001), clearly plays a role. The lack of inorganic phosphate in culture medium containing glucose supports embryo development in strains that would normally show developmental arrest in the combined presence of glucose and inorganic phosphate (Scott and Whittingham, 1996). Any glucose that enters the embryo is rapidly and irreversibly phosphorylated by hexokinase to form glucose6-phosphate (Barbehenn et al., 1974). Subsequent utilization of glucose-6-phosphate in glycolysis is blocked in early embryonic development and this block is thought to occur at the enzyme phosphofructokinase, which converts fructose-6-phosphate to fructose-1,6-phosphate (Barbehenn et al., 1978). Without a control mechanism to limit either the uptake or phosphorylation of glucose, a concentration gradient would be maintained leading to unphysiological concentrations of glucose-6-phosphate. Normally, hexokinase is regulated allosterically by its product, glucose-6phosphate, but this mechanism is inhibited by inorganic phosphate (L. Scott and D. G. Whittingham, unpublished). The inhibitor phloretin may aid development by preventing the uptake of glucose when embryos are placed in culture media containing both glucose and inorganic phosphate. When the phloretin is removed too early in development, glucose may flood into the embryo, causing in a rapid build-up of glucose-6-phosphate and depletion of ATP, and resulting in the developmental blocks recorded.

Apart from the inhibition of facilitative glucose uptake, phloretin may also affect other transporter functions in the embryo. It has been shown that water can be transported into cells by the glucose transporters and that this process is inhibited by phloretin (macrophages: Fischbarg et al., 1989; Loike et al., 1993; ram and human spermatozoa: Curry et al., 1995). However, Echevarria and Verkman (1992) did not find any direct connection between the transport of glucose and water in macrophages. Different types of cells demonstrate the coupling of urea-water transport in culture, and this process is inhibited by phloretin (Smith et al., 1995). In the data presented here, phloretin was toxic at high concentrations and, in CF-1 embryos in particular, displayed an effect that was unrelated to the glucoseinorganic phosphate-mediated block in, and retardation of, development. If long-term culture of embryos in phloretincontaining medium also inhibits water transport or the exchange of ammonium products, development could be compromised. This may also explain the inhibition of blastocyst formation seen by Leppens-Luisier et al. (2001) when embryos were cultured continually in phloretin.

Certain types of cells are known to suffer from glucose toxicity under culture conditions that lead to the overinduction of glucose transporters. It is possible that in embryos that show developmental arrest in vitro there is an overinduction of the glucose transport mechanism when they are placed in unphysiologically high concentrations of glucose. This situation could result in too much glucose entering the embryo, with the subsequent depletion of ATP reserves necessary for the transcription and translation of the embryonic genome. Alternatively, overinduction of glucose transport could result in a build up of glucose-6phosphate to concentrations that are toxic to the embryo, preventing further development. Embryos that do not appear to suffer from a glucose-inorganic phosphate-linked developmental block $\left(\mathrm{F}_{2}\right)$ may have no inducible form of glucose transporters at the early stages of preimplantation development or may have transporters that are under tight control.

In the present study, CF-1 embryos were the most sensitive to both glucose and inorganic phosphate. The inhibition of glucose by the agent phloretin increased development but did not overcome the sensitivity of the embryos to inorganic phosphate. When the entry of glucose into CD-1 embryos by facilitative transport was blocked by the inhibitor phloretin, the embryos developed through the two-cell developmental block regardless of the presence of inorganic phosphate. $F_{2}$ embryos do not show developmental arrest, and are not grossly affected by glucose or inorganic phosphate concentrations or by inhibition of glucose transport.

The results of the present study and data on the low glucose environment that embryos are subjected to in vivo (Gardner and Sakkas, 1993; Gardner et al., 1996) indicate that the glucose-inorganic phosphate-induced two-cell block in, and retardation of, development seen in vitro in mouse embryos could be due to the unphysiological culture conditions. By limiting or inhibiting the uptake of glucose by pronuclear embryos during the first few hours of development, the block in development at the two-cell stage can be avoided. If the glucose is reduced substantially ( 5.5 or $2.78 \mathrm{mmol} \mathrm{I}^{-1}$ to 1.0 or $0.5 \mathrm{mmol} \mathrm{I}^{-1}$ ), the beneficial effects of having glucose available for metabolism at later developmental stages can be appreciated. The difference between CF-1, CD-1 and $F_{2}$ embryos in terms of optimum glucose concentration, sensitivity to inorganic phosphate and response to phloretin may indicate a difference in: (i) the isotype of glucose transporters in the embryonic membrane; (ii) the number of transporters available during early embryo development, (iii) the ability of the embryo to convert glucose-6-phosphate into glycogen; or (iv) the lack of ability of the embryos to control the uptake of inorganic phosphate.

\section{References}

Aghayan M, Rao LV, Smith RM, Jarrett L, Charron MJ, Thorens B and Heyner S (1992) Developmental expression and cellular localization of glucose transporter molecules during mouse preimplantation development Development 115 305-312

Barbehenn EK, Wales RG and Lowry OH (1974) The explanation for the blockade of glycolysis in early mouse embryos Proceedings National Academy of Sciences USA 71 1056-1060

Barbehenn EK, Wales RG and Lowry OH (1978) Measurement of metabolites in single preimplantation embryos: a new means to study metabolic control in early embryos Journal of Embryology and Experimental Morphology 43 29-46 
Bell GI, Kayano JB, Buse CF, Burant J, Takeda D, Lin H, Fukumoto S and Seino SDC (1990) Molecular biology of mammalian glucose transporters Diabetes Care 13 198-208

Biggers JD, Whittingham DG and Donahue RP (1967) The pattern of energy metabolism in the mouse oocyte and zygote Proceedings National Academy of Sciences USA 58 560-567

Brinster RL (1965a) Studies on the development of mouse embryos in vitro. IV. Interaction of energy sources Journal of Reproduction and Fertility 10 $227-240$

Brinster RL (1965b) Studies on the development of mouse embryos in vitro. II. The effect of energy source Journal of Experimental Zoology 158 59-68

Brown JJG and Whittingham DG (1992) The dynamic provision of different energy substrates improves development of one-cell random bred mouse embryos in vitro. Journal of Reproduction and Fertility 95 503-511

Carayannopoulos M, Chi M, Cui Y, Pingsterhaus J, McKnight R, Muekler M, Devaskar S and Moley K (2000) GLUT8 is a glucose transporter responsible for insulin-stimulated glucose uptake in the blastocyst Proceedings National Academy of Sciences USA 97 7313-7318

Chatot CL, Lewis JL, Torres I and Ziomek CA (1990) Development of 1-cell embryos from different strains of mice in CZB medium Biology of Reproduction 42 432-440

Chatot CL, Lewis-Williams J, Torres I and Ziomek CA (1994) One-minute exposure of 4-cell mouse embryos to glucose overcomes morula block in CZB medium Molecular Reproduction and Development 37 407-412

Chi M, Manchester J, Basuray R, Mahendra S, Strickler R, McDougal D and Lowry O (1993) An unusal active hexose transport system in human and mouse preimplantation embryos Proceedings National Academy of Sciences USA $9010023-10025$

Curry MR, Miller JD and Watson PF (1995) The presence of water channel proteins in ram and human sperm membranes Journal of Reproduction and Fertility 104 297-303

Echevarria M and Verkman AS (1992) Optical measurement of osmotic water transport in cultured cells. Role of glucose transporters Journal of General Physiology 99 573-589

Fischbarg J, Kuang K, Hirsch J, Lecuona S, Rogozinski L, Silverstein SC and Loike J (1989) Evidence that the glucose transporter serves as a water channel in 1774 macrophages Proceedings National Academy of Sciences USA 86 8397-8401

Gardner DK and Leese HJ (1988) The role of glucose and pyruvate transport in regulating nutrient utilization by preimplantation mouse embryos Development $104423-429$

Gardner DK and Sakkas D (1993) Mouse embryo cleavage, metabolism and viability: role of medium composition Human Reproduction 8 288-295

Gardner DK, Lane M, Calderon I and Leeton J (1996) Environment of the preimplantation embryoin in vivo: metabolite analysis of oviduct and uterine fluids and metabolism of cumulus cells Fertility and Sterility 65 349-353
Hogan A, Heyner S, Charron MJ, Copeland NG, Gilbert DJ, Jenkins NA Thorens B and Schultz GA (1991) Glucose transporter gene expression in early mouse embryos Development 113 363-372

Houghton FD, Sheth B, Moran B, Leese HJ and Fleming TP (1996) Expression and activity of hexokinase in the early mouse embryo Molecular Human Reproduction 1 793-798

Ibberson M, Uldry M and Thorens B (2000) GLUTXI, a novel mammalian glucose transporter expressed in the central nervous system and insulinsensitive tissues Journal of Biological Chemistry 275 4607-4612

Kasanicki MA and Pilch PF (1990) Regulation of glucose transporter function Diabetes Care 13 219-223

Lawrence CJ, Hiken JF and James DE (1990) Stimulation of glucose transport and glucose transporter phosphorylation by oxadaic acid in rat adipocytes Journal of Biological Chemistry 26519 768-19 776

Leese HJ (1991) Metabolism of the preimplantation mammalian embryo. In Oxford Reviews of Reproductive Biology pp 35-72 Ed. SR Milligan. Oxford University Press, Oxford

Leppens-Luisier G, Urner F and Sakkas D (2001) Facilitated glucose transporters play a crucial role throughout mouse preimplantation embryo development Human Reproduction 16 1229-1236

Loike JD, Cao L, Kuang K, Vera JC, Silverstein SC and Fischbarg J (1993) Role of glucose transporters in diffusional water permeability through J774 cells Journal of General Physiology 102 897-906

Moley K, Chi M and Muekler M (1998) Maternal hyperglycemia alters glucose transport and utilization in mouse preimplanation embryos American Journal of Physiology 275 E38-E47

Pantaleon M, Harvey M and Pascoe W (1997) Glucose transporter GLUT3: ontogeny targeting and role in mouse blastocysts Proceedings National Academy of Sciences USA 94 3795-3800

Pantaleon M, Ryan J, Gil M and Kaye P (2001) An unusual subcellular localization of Glut1 and link with metabolism in oocytes and preimplanation mouse embryos Biology of Reproduction 64 1247-1254

Scott LA and Whittingham DG (1996) The influence of genetic background and media components on the development of mouse embryos in vitro. Molecular Reproduction and Development 43 336-346

Scott LA, Sundaram S and Smith S (1993) The relevance and use of mouse embryo bioassays for quality control in an assisted reproductive technology program Fertility and Sterility 60 559-568

Smith CP, Lee WS, Martial S, Knepper MA, You G, Sands JM and Hediger MA (1995) Cloning and regulation of expression of the rat kidney urea transporter (rUT2) Journal of Clinical Investigation 96 1556-1563

Received 19 July 2001.

First decision 24 August 2001.

Final manuscript received 25 January 2002.

Accepted 28 January 2002. 